\title{
Labour supply, efficient bargains and countervailing power.
}

\author{
Robin A. Naylor \\ University of Warwick
}

March 2002

\section{Abstract}

We develop a theoretical model of individual labour supply in which the canonical model of the competitive labour market emerges as a special case. More generally, we are able to characterise labour supply behaviour when, in the absence of a continuum of jobs, firms are able to push workers on to lower indifference curves and off their labour supply curve. We show that in such circumstances wage-hours combinations are likely to be characterised by a contract curve which lies between the worker's labour supply and marginal productivity schedules. Accordingly, workers work more hours than they would choose at given wage rates. Against this, if workers have sufficient countervailing power (deriving from union representation, for example), then a negativelysloped contract curve can extend through wage-hours bundles above the competitive outcome with actual hours being less than preferred hours at given wages. We argue that various predictions of the model are consistent with recent empirical analysis of hours worked of British men (see Stewart and Swaffield $(1995,1997)$ ). We also show that neither minimum wage nor maximum hours regulation each on its own - is likely to be of benefit to workers: only when they are combined are they likely to raise the welfare of the low-paid working long hours.

JEL Classification No.: J22, J33, J42

Address for correspondence: Department of Economics, University of Warwick, Coventry, CV4 7AL, England, UK.

Tel.: 024 76523529. Fax: 024 76523032. E-mail: robin.naylor@warwick.ac.uk 


\section{Introduction}

In the canonical model of labour supply, utility-maximising workers are assumed to be free to choose their optimal hours of work at any given wage rate. This theoretical model not only underlies much macroeconomic analysis, but also provides the framework in which econometric evidence on labour supply is typically interpreted and on which tax and related microeconomic policy options including welfare and labour market interventions - are then designed.

Dissatisfaction with this orthodox model has focussed on the observation that for most workers the length of the working week is chosen by the firm. Hence, only if there is a continuum of jobs will workers be able to equate a given market wage to their marginal rate of substitution between income and leisure. Against this, there is growing evidence of workers for whom the wagehours combination lies off their labour supply curves. Section 2 of this paper summarises some of this evidence.

In the current paper, we develop a theoretical model of individual labour supply in which the canonical model emerges as a special case. More generally, we are able to characterise labour supply behaviour when, in the absence of a continuum of jobs, firms are able to push workers on to lower indifference curves than that corresponding to the tangency condition of orthodox theory: i.e., to the right of the labour supply curve. The extent to which the firm is able to do this is shown to depend upon a number of factors, which include the state of the local labour market and the extent of any countervailing power available to the worker, such as insider power or trade union representation. Indeed, if the worker is sufficiently powerful it is possible that the wage will be pushed above the marginal value product of the worker's labour in which case hours worked will be to the left of the worker's labour supply curve: this can be thought of as equivalent to the case developed in Oswald and Walker (1993). 
As with Oswald and Walker (1993), the model can generate a downward-sloping efficiency locus in wage-hours space. This can occur even if there is an underlying positively-sloped labour supply curve characterising the worker's unconstrained optimal choice of hours for a given wage. Unlike Oswald and Walker (1993), the efficiency locus describes the wage-hours combinations for both unionised and non-unionised workers and can exist at wage rates below the level which would obtain in a perfectly competitive market and hence, it is shown, will lie to the right of the unconstrained labour supply curve for such wage levels. The existence of such a wage-hours locus has a number of further implications. First, it is consistent with empirical evidence showing workers' actual hours to exceed desired hours for given wage rates. Second, it has implications for the analyses both of monopsony power in the labour market and of the union- nonunion wage differential. Third, it offers a possible re-interpretation of the stylised fact of a backward-bending labour supply curve.

In the traditional model of static monopsony, the individual firm is assumed to face a positively sloped labour supply curve and is able to push wages below the level which would obtain in a perfectly competitive labour market. As the wage falls, the number of workers offering to supply labour to the firm diminishes. Thus, the model typically ignores the possibility that individual workers continue to offer labour to the firm but adjust their optimal wage-hours bundle. In the current paper, in contrast, we allow not only for this possibility, but also for the case in which the firm is able to push the worker off his or her labour supply curve. The wage-hours combination then lies on a contract curve rather than on the supply curve. Accordingly, the model can be interpreted as an efficient bargaining model of monopsony.

In terms of policy implications, the model predicts that the imposition of maximum hours regulations - such as occurred in the UK with the implementation in 1998 of the EU Directive on Working Time - will be unlikely to improve the overall remuneration package of workers. This is 
because workers whose hours are likely to be affected by the legislation will face pressure from monopsony employers to reduce the hourly wage rate to compensate for the profit-damaging restriction on weekly hours. Similarly, minimum wage legislation - as passed in the UK in 1998 (see Metcalf (1999) for a discussion) - will induce low-paying firms to raise weekly hours if this is possible: again, affected workers will not benefit where employers are able to push them to a reservation utility level. Instead, a corollary of the model is that workers will gain only if both maximum hours and minimum wage legislation are introduced: as occurred in the UK in the late 1990s.

In the standard theoretical model of union-firm bargaining, the union is assumed to be bargaining for a wage in excess of the competitive wage which would obtain in the absence of unions. It is well-known that the resulting wage gain, assumed to be positive, is not accurately measured by the union-nonunion wage gap for the simple reason that in a partially unionised labour market the non-union wage need not correspond to the competitive wage of a non-unionised labour market. Nonetheless, econometric evidence of positive union-nonunion wage differentials is typically interpreted as implying that union wages exceed the level which would prevail in a competitive labour market and that a reduction in union bargaining power would induce union wages to fall towards the competitive outcome. In the current paper, any union bargaining power is interpreted as a countervailing power enabling workers to resist the employer's attempt to push them to lower wage outcomes along a contract curve. In this context, it is clear that one can infer nothing about union wages relative to a benchmark competitive wage, from empirical estimates of positive unionnonunion wage differentials.

The rest of this paper is organised as follows. In the next section of the paper we summarise relevant empirical and econometric evidence. Section 3 outlines the theoretical model and Section 4 presents a comparative static analysis of the properties of the model together with a discussion of 
predictions and implications in the context of labour market policy interventions. Section 5 closes the paper with a summary and suggestions for further work.

\section{Evidence}

Conventional wisdom suggests that, over time, economic growth will be associated with a reduction in the length of the working week. This view is consistent with the idea of leisure as a normal good, demand for which is increasing with income. Indeed, international evidence supports the hypothesis for many countries and over a long sweep of time. For both the UK and the US, for example, there was a secular decline in average weekly hours throughout most of the twentieth century: average hours were about 55 per week in both countries in 1900 and about 40 per week by the latter part of the century.

In the UK, however, a very unusual picture was emerging in the latter years of the twentieth century. Average hours actually increased in the UK from the mid-1980s and diverged substantially from average hours in the rest of the EU. Table 1 shows hours usually worked per week for male employees working full-time in the EU for 1991. The UK is clearly an outlier with an average of 45.2 compared to an average of 40.2 in the rest of the EU. The UK is also seen to be an extreme case with over one-third of male full-time industrial employees working 46 hours or more, compared to an EU average of $10.7 \%$ (and a non-UK EU average of less than 6\%). Indeed, only Greece and Ireland have a figure of more than $10 \%$. The figures for 1999 are very similar to those for 1991.

From these figures one can see why the EU Directive on Working Hours has been more contentious in the UK than elsewhere: the regulation of a 48 hour maximum required workweek is unlikely to be a binding constraint outside the UK. Indeed, a number of other EU states have national maxima considerably below the 48-hour limit in the Directive. 
In addition to this evidence on the length of the workweek in the UK, there is also evidence that workers would prefer to work fewer hours at their hourly wage rate. Stewart and Swaffield (1995), for example, using information from the British Household Panel Survey (1991) find that about $44 \%$ of male employees aged 21-64, indicated that their desired hours - at their current wage rate - were different from their actual hours, and hence that they are off their labour supply curve. Of these workers, the majority (36.3\% of the whole sample) indicated a preference to work fewer hours at the prevailing hourly wage rate. Table 2 shows both the hours preferences for 1991, taken from Stewart and Swaffield (1995) and the author's own calculations for 1992-1999. The breakdown over time in hours preferences is quite stable.

Additionally, evidence from the British Social Attitudes Surveys (BSAS) is consistent with the view that workers are working more hours than they would freely choose. For example, in the BSAS for 1990, 30 percent of workers indicated that they would prefer a job in which they worked fewer hours. Oswald (1995) has observed that the question in BSAS does not explicitly state that the wage rate would be constant if hours varied and noted that when workers are asked if they would still like to work fewer hours even if it meant earning less money as a result, only $7 \%$ of workers respond in the affirmative. The question structure seems less clear than in the BHPS. Further evidence comes form the European Economy $(1989,1994)$ figures on hours preferences across EU countries. For the UK, only $48 \%$ of workers were happy with their hours in 1994, while $39 \%$ would have preferred to work fewer hours. Across the EU, $46 \%$ of workers would have chosen the same hours (very similar to the UK figure) and $31 \%$ would have chosen fewer hours (a smaller percentage than in the UK). Between 1989 and 1994, the percentage of workers happy with their hours fell from $51 \%$ to $46 \%$.

Stewart and Swaffield (1995, 1997), using 1991 BHPS data, analyse the breakdown of workers' hours preferences by various characteristics. They show that workers are more likely to 
prefer shorter hours (i) the longer are the hours they work (ii) the greater is the level of unemployment in the local labour market and (iii) if they are non-unionised. On the issue of unionisation, Oswald and Walker (1993) develop a contract model of labour supply in which unionised workers are off their labour supply curve. Analysing Family Expenditure Survey data, they find that the contract model is consistent with the data for the union sector.

In the current paper, we develop a non-competitive labour supply model and focus on the extent to which the properties of the model are consistent with the evidence on labour supply and worker's hours preferences.

\section{The theoretical model}

In this Section of the paper, we first provide an intuitive description of the model before subsequently developing the more formal analysis.

In the canonical model of labour supply each worker chooses optimal hours, $\mathrm{h}^{*}$, for a given wage rate, w, and non-labour income, $\mathrm{m}$, in order to maximise utility defined over income (or consumption), c, and leisure, 1 . For given w, if the worker is constrained to work a number of hours different from $\mathrm{h}^{*}$, then utility will be sub-optimal. The optimising labour supply decision is normally represented in income-leisure space, but we can also represent the problem by the family of indifference curves plotted in (w, h)-space, as shown in Figure 1. Higher indifference curves represent greater levels of utility. 


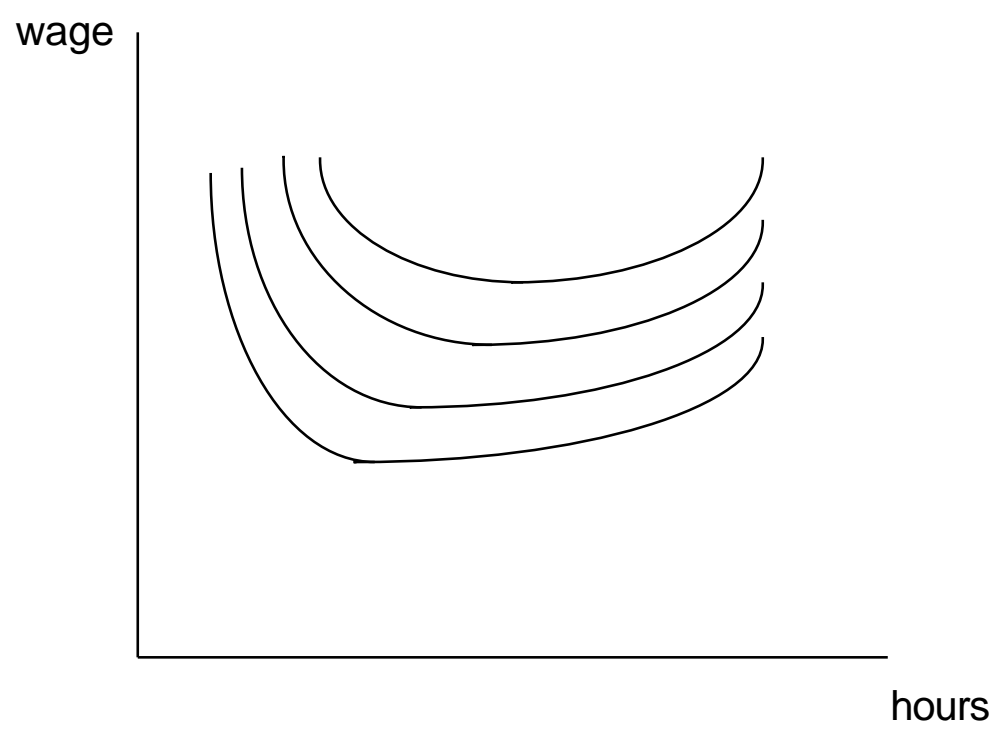

Figure 1. Indifference curves in (w, h) - space

In terms of Figure 1, the labour supply curve of the canonical model is, of course, the locus of turning points of the indifference curves, showing the choice of hours associated with the highest obtainable indifference curve for any wage rate. In Figure 1, the underlying labour supply curve is implicitly positively-sloped, although in general this need not be the case.

The worker can be assumed to choose a job offering a wage-hours bundle which maximises the worker's utility. If, at any given wage, there is a continuum of jobs, then the worker will be able to select hours along the labour supply curve. Suppose initially that the representative worker is on the labour supply curve supplying $\mathrm{h}$ hours to a particular firm at a wage rate w and attaining indifference curve $\mathrm{U}_{1}$, as shown in Figure 2. Suppose further that the wage, $\mathrm{w}_{1}$, is just equal to the marginal product of the worker's labour at $\mathrm{h}$. The marginal product of the worker's labour is assumed to be diminishing. 


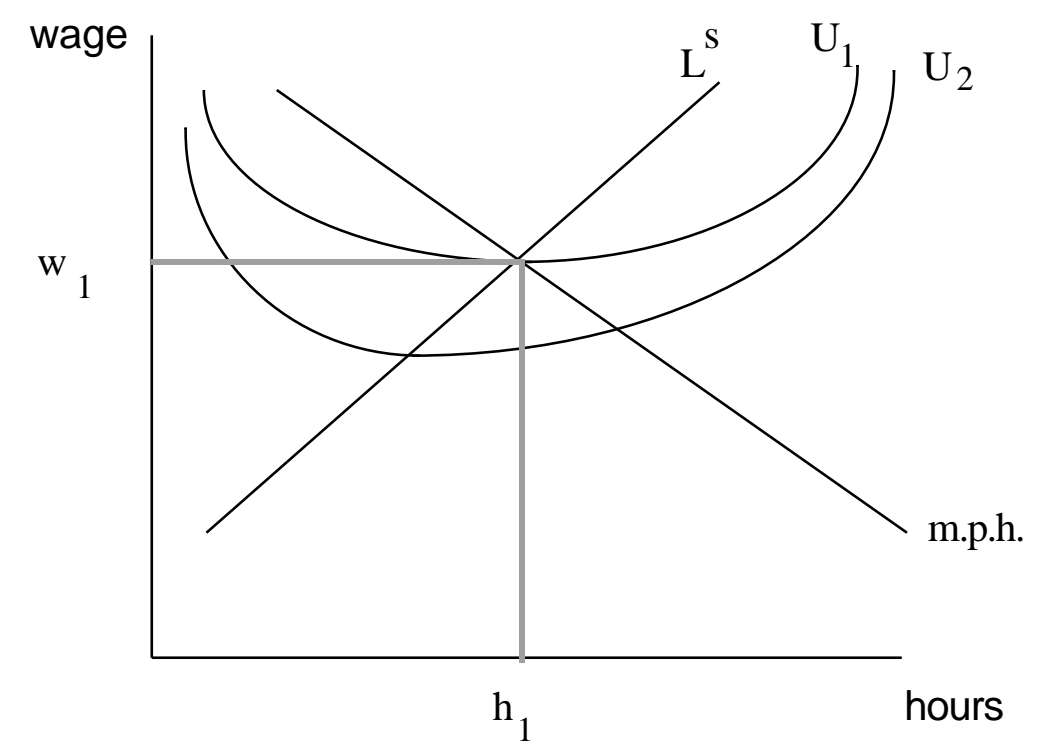

Figure 2. Indifference curves and marginal productivity

If the firm attempts to alter the wage-hours bundle in such a way that the worker's utility falls, for example by reducing the wage or increasing the workweek, and if other jobs with wage-hours bundles yielding $\mathrm{U}_{1}$ utility are costlessly available to the worker, then the worker would quit this employment. But suppose that the utility level associated with the worker's next best alternative activity is less than $U_{1}$, say $U_{2}$, for example. Then this gives the firm some scope for offering the worker a wage-hours bundle which pushes the worker off the labour supply curve. What wagehours bundle would a profit-maximising employer select? It would be that bundle which maximised the firm's profit from this representative worker, subject to satisfying the minimum worker-utility constraint. Such a bundle would lie on an efficiency locus representing points of tangency between the worker's indifference curves and the firm's iso-profit curves for the representative worker. The efficiency locus is shown in Figure 3. 


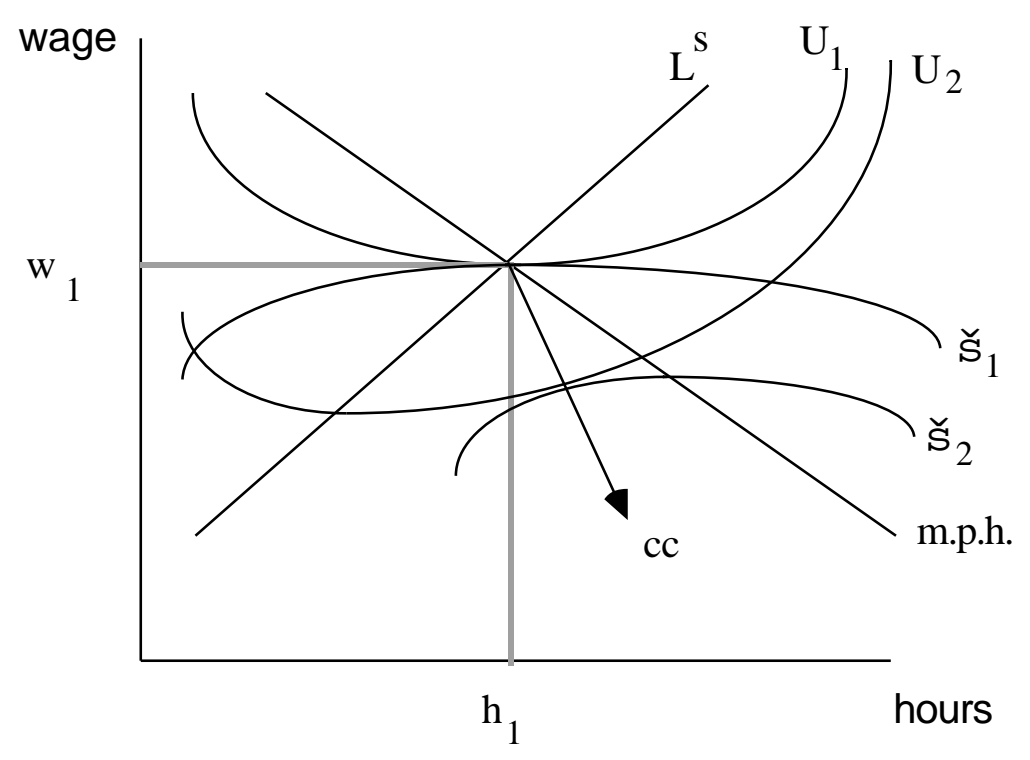

Figure 3. The efficiency locus

Along the contract curve, the individual worker is working more hours than would be optimally chosen for any wage rate. Similarly, the marginal product of the worker's labour exceeds the wage rate. This outcome occurs because the worker's next best alternative activity yields an alternative utility level below that associated with the competitive outcome. Hence, the employer is able to extract a rent from the worker. Such rent might have a number of sources. If workers are heterogeneous, then the marginal worker may have utility equal to reservation utility in the competitive equilibrium, but intra-marginal workers will experience some rent. Similarly, even in the presence of alternative job opportunities, firm-specific skills, search and mobility costs will enable firms to exercise a degree of monopsony power. Furthermore, if there is high unemployment in the local labour market with few alternative employment opportunities, then this too will give the firm potential to push the worker down the contract curve: exercising a degree of monopsony power. The alternative utility level sets the lower bound on the contract curve. The lower is the worker's outside 
utility, the further the firm is able to push the outcome down the contract curve. ${ }^{1}$ If the worker has any countervailing bargaining power, for example through union representation or 'insider' status, then he or she might be able to resist being pushed to the lower bound of the contract curve.

Indeed, it is possible that the worker's bargaining power might outweigh that of the firm. In this case, it is possible that the contract curve will extend upward above the competitive benchmark with the wage exceeding the worker's marginal product. In such a case, as illustrated in Figure 4, the contract curve will be bounded by a minimum iso-profit curve reflecting the value of the worker's average product in this employment.

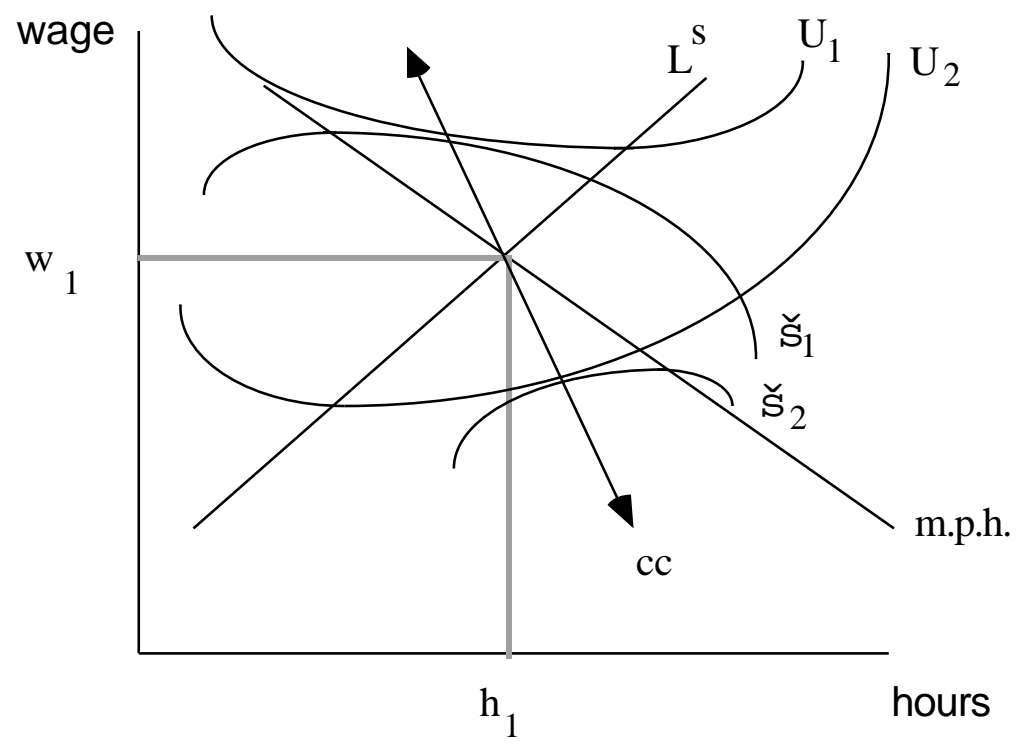

Figure 4. The general case of the contract curve

We turn now to examine the properties of this contract curve in a more formal representation of the model.

1 This analysis corresponds with an industrial relations literature linking diminished worker bargaining power with a process of intensification of the labour process (see, for example, Marginson and Nolan ()). 


\section{Formal model}

For simplicity, we examine the case of the linear labour supply function:

$$
\mathrm{h}=\alpha \mathrm{w}+\beta \mathrm{m}+\gamma
$$

where $\mathrm{h}$ is hours worked, $\mathrm{w}$ is the hourly wage rate and $\mathrm{m}$ is non-labour income. In this case, as is well known, if $\alpha=0$ and $\beta=0$, then $h=0$ is sufficient for the Slutsky condition to be satisfied.

The direct utility function associated with the linear labour supply curve can be written as:

$$
\mathrm{U}(\mathrm{c}, \mathrm{h})=\frac{1}{\beta^{2}}[\beta \mathrm{h}-\alpha] \exp \left\{\frac{\beta(\mathrm{h}-\beta \mathrm{c}-\gamma)}{\alpha-\beta \mathrm{h}}\right\}
$$

where $\mathrm{c}=\mathrm{wh}+\mathrm{m}$ is consumption. Substituting this expression for $\mathrm{c}$ into (2) yields:

$$
\mathrm{U}(\mathrm{w}, \mathrm{h})=\frac{1}{\beta^{2}}[\beta \mathrm{h}-\alpha] \exp \left\{\frac{\beta(\mathrm{h}-\beta \mathrm{wh}-\beta \mathrm{m}-\gamma)}{\alpha-\beta \mathrm{h}}\right\}
$$

Taking logs and re-arranging, (3) yields:

$$
2 \log \beta+\log U-\log (\beta \mathrm{h}-\alpha)=\frac{\beta(\mathrm{h}-\beta \mathrm{wh}-\beta \mathrm{m}-\gamma)}{\alpha-\beta \mathrm{h}}
$$

which implies that:

$$
\mathrm{w}=\frac{1}{\beta \mathrm{h}}\left\{\mathrm{h}-\beta \mathrm{m}-\gamma-\left[\frac{\alpha-\beta \mathrm{h}}{\beta}\right][2 \log \beta+\log \mathrm{U}-\log (\beta \mathrm{h}-\alpha)]\right\}
$$

Equation (5) represents the expression for the indifference curve in (w, h)-space. Differentiation of (5) with respect to $h$ produces an expression for the slope of the indifference curve:

$$
\frac{\mathrm{dw}}{\mathrm{dh}}=\frac{1}{\beta \mathrm{h}}\left\{2 \log \beta+\log \mathrm{U}-\log (\beta \mathrm{h}-\alpha)-\beta \mathrm{w}_{f}\right.
$$

Substituting (5) in (6) and re-arranging yields:

$$
\frac{\mathrm{dw}}{\mathrm{dh}}=\frac{1}{\mathrm{~h}[\alpha-\beta \mathrm{h}]}\left\{\mathrm{h}-\alpha \mathrm{w}-\beta \mathrm{m}-\gamma_{\gamma}\right.
$$

From (7), it is readily checked that the indifference curve has zero slope at the point of intersection with the labour supply curve, $h=\alpha w+\beta m+\gamma$ and is positively (negatively) sloped to the right (left) of the supply curve. 
In order to derive an expression for the contract curve depicted in Figure 4, it is necessary to specify the firm's profit as a function of the hours worked by the representative employee. This is given by equation (8):

$$
\mathrm{p}=\mathrm{R}(\mathrm{h})-\mathrm{wh}
$$

where $\mathrm{p}$ is profit associated with the representative worker and $\mathrm{R}$ is the value of the worker's product. It is assumed that $\mathrm{R}^{\prime}(\mathrm{h})>0$ and $\mathrm{R}^{\prime \prime}(\mathrm{h})<0$. Re-arranging:

$$
\mathrm{w}=\frac{\mathrm{R}(\mathrm{h})-\pi}{\mathrm{h}}
$$

For given p, differentiating (9) with respect to $\mathrm{h}$ gives an expression for the slope of the iso-profit curve:

$$
\frac{\mathrm{dw}}{\mathrm{dh}}=\frac{\mathrm{R}^{\prime}(\mathrm{h})-\mathrm{w}}{\mathrm{h}}
$$

The contract curve is the locus of points of tangency between the iso-profit curves and the indifference curves of the representative worker. Hence, it follows from equations (7) and (10) that the contract curve is such that:

$$
\frac{\mathrm{h}-\alpha \mathrm{w}-\beta \mathrm{m}-\gamma}{(\alpha-\beta \mathrm{h}) \mathrm{h}}=\frac{\mathrm{R}^{\prime}(\mathrm{h})-\mathrm{w}}{\mathrm{h}}
$$

Re-arranging, we obtain

$$
\mathrm{w}=\frac{1}{\beta \mathrm{h}}\left[\mathrm{h}-\beta \mathrm{m}-\gamma-(\alpha-\beta \mathrm{h}) \mathrm{R}^{\prime}(\mathrm{h})\right]
$$

as the equation of the contract curve.

We turn now to investigate the comparative static properties of the model.

\section{Properties of the model}

From equation (12), we can derive the expression for the slope of the contract curve. This is given by equation (13): 


$$
\frac{\mathrm{dw}}{\mathrm{dh}}=\frac{1}{\beta \mathrm{h}}\left[1+\beta\left(\mathrm{R}^{\prime}(\mathrm{h})-\mathrm{w}\right)-(\alpha-\beta \mathrm{h}) \mathrm{R}^{\prime \prime}(\mathrm{h})\right]
$$

Property 1

At the competitive market outcome, where the contract curve passes through the point of intersection of the marginal product and labour supply curves, $R^{\prime}(h)=w$ and hence, assuming leisure to be normal, the contract curve has a negative slope.

This follows because $(1 / \beta \mathrm{h})<0$, if leisure is normal, whilst the terms inside the square brackets have a positive sum: $\beta\left(R^{\prime}(h)-w\right)$ equals zero at the competitive outcome, $R^{\prime \prime}(h)$ is negative under the assumption of a diminishing marginal product of hours, and $\alpha-\beta \mathrm{h}$ is positive if the Slutsky condition is satisfied.

It follows from continuity, at least in the neighbourhood of the competitive outcome, that if the firm is able to push the representative worker down the contract curve and onto a lower indifference curve, not only will the worker's wage fall but also the hours worked will rise. This might occur if either the relative bargaining power of the firm increases, for example through legislative changes, or if the worker's alternative employment opportunities, and hence outside utility, deteriorate. Thus, the model would predict that, ceteris paribus, wage rates will be lower and hours worked will be greater the higher is the level of unemployment in the local labour market. Conversely, where workers have sufficient bargaining power to negotiate wage rates above the competitive level, these bargains will be associated with fewer hours worked than in the competitive case.

This property of the model explains evidence that workers are off their labour supply curves - supplying more hours than they would choose at their wage rates - as being a consequence of employer monopsony power. The property of the model is also consistent with the finding of Stewart and Swaffield (1996) that the probability of an individual working more hours than he or she wishes is an increasing function of the local unemployment rate. 
A corollary of Property 1 - and, in particular, the negative slope of the contract curve - is that, at least in the neighbourhood of the competitive outcome, workers who are working longer hours will be those who are off their labour supply curve to the right. Thus we would expect long hours and a preference for short hours to be positively correlated, which is consistent with the evidence reported by Stewart and Swaffield (1997).

Property 2

The contract curve is negatively-sloped when the worker's wage exceeds the value of the marginal product.

It follows from equation (13) that, under our assumptions, dw/dh is negative if $\mathrm{R}^{\prime}(\mathrm{h})<\mathrm{w}$. This result is consistent with the analysis of Oswald and Walker (1993) who derive a negatively-sloped contract curve for unionised workers. The prediction that, ceteris paribus, union workers will be further up the contract curve working fewer hours for a higher wage rate compared to nonunion workers is also consistent with the evidence. The existence of a union-nonunion wage gap is well-established. With respect to hours worked, Stewart and Swaffield report from the 1991 BHPS that individuals covered by a trade union work 1.7 hours less per week than those not covered. This is consistent with the theoretical prediction.

Property 3

For any wage less than the competitive wage, hours worked exceed not only desired hours at that wage but also desired hours at the competitive wage.

This would be self-evident were we able to show that the contract curve is negatively-sloped for all $w>R^{\prime}(h)$. It appears from (13), however, that there is no intuitively simple sufficiency condition for this. Instead, it can be shown that for solutions on the contract curve associated with wages 
below the competitive level, hours worked must be in excess of competitive hours. To show this, consider equation (12) re-written as:

$$
\mathrm{w}=\mathrm{R}^{\prime}(\mathrm{h})+\frac{\alpha}{\beta \mathrm{h}}\left[\frac{\mathrm{h}-\beta \mathrm{m}-\gamma}{\alpha}-\mathrm{R}^{\prime}(\mathrm{h})\right]
$$

Expressed in this form, it is apparent that the contract curve is given by the marginal product schedule minus a proportion of the difference between the labour supply and marginal product schedules, where the proportion is not fixed but varies with hours worked.

From (14), if $w<R^{\prime}(h)$, it follows that $R^{\prime}(h)<(h-\beta m-\gamma) / \alpha$ and hence that $h$ is such that the labour supply curve lies above the marginal product curve. Thus it follows that $\mathrm{h}$ is greater than hours worked in the competitive equilibrium.

A corollary of this result is that below the competitive outcome, the contract curve lies everywhere to the right of the labour supply curve and hence that in this region of the contract curve the worker is working more hours than he or she would choose, given the wage rate. Workers are off their labour supply curves. This is also true for outcomes on the contract curve above the competitive equilibrium: in this case, however, workers are working fewer hours than they would choose given the wage rate. Outside the special case of the competitive equilibrium, the wage-hours outcome lies off both the labour demand and the labour supply curves. From this perspective, the competitive equilibrium can be seen as a special case of the more general contract curve model, occurring when any monopoly bargaining power on the part of the worker (deriving from, say, skillspecificity or union representation) just offsets any monopsony power on the part of the firm (deriving from limited employment opportunities in the local labour market, for example).

In general, it is likely that trade union representation will enhance the worker's bargaining strength. In the model of Oswald and Walker (1993), for example, union bargaining raises wage rates and reduces hours worked relative to the competitive equilibrium. In the Oswald and Walker model the contract curve exists only above the competitive outcome, in the presence of union 
bargaining power. In the current paper, the contract extends also below the competitive outcome in the presence of bargaining power by the firm, deriving from limited outside options of workers. In this more general framework, any union bargaining power can be seen as a countervailing power. If the worker's bargaining power only partially offsets the firm's bargaining strength, then unionised workers will receive wages which, though they may exceed the counterfactual non-union level, will nonetheless be below the benchmark competitive level.

Property 4

If wages are below the competitive level, then - by itself - maximum hours legislation will not succeed in raising workers utility. Similarly, on its own, minimum wage legislation will not raise worker utility.

Below the competitive equilibrium - where hours are longer and wages lower - the imposition of a maximum hours constraint will induce firms to optimise subject not only to the reservation utility level but also to the hours constraint. In this situation, the profit-maximising solution will no longer be on the contract curve but will be at that point on the reservation utility curve at the maximum hours level. As a consequence, workers do not gain from hours regulation. Essentially, monposony firms adjust to the regulation by requiring workers to trade off the benefit of an hours reduction with the disutility of a wage cut.

Similarly, on its own, minimum wage legislation raising wages at levels below the competitive level does not induce a utility gain for workers. Instead, workers gain only if minimum wages and maximum hours are imposed simultaneously. By coincidence, this is what has happened in the UK in recent years and, therefore, the prospects for the legislation to have been of genuine benefit to low-paid workers have been enhanced. 


\section{Concluding remarks}

In most jobs workers are not free to choose the number of hours they would like to work at the given wage rate. Thus, the conventional labour supply model, in which the worker's wage-hours combination corresponds to the tangency point at which the marginal wage rate equals the marginal disutility of hours, is valid only if workers face a continuum of jobs. In the absence of this, it is possible that workers will be employed in jobs with hours requirements putting workers off their labour supply curves. If a worker has no alternative employment opportunities other than with the current employer, then there is the potential for the firm to offer the worker a wage-hours bundle yielding a utility as low as the worker's reservation utility level. The current paper develops the concept of a contract curve, which is a locus of wage-hours bundles extending downwards from the perfectly competitive outcome toward the reservation utility threshold. In the presence of alternative employment opportunities the contract curve will be bounded below by the utility level associated with the worker's next best job alternative.

The properties of the contract curve model have been analysed and particular implications drawn out. First, it has been shown that for outcomes which, to the worker, are inferior to the competitive outcome, not only are wages lower than competitive wages but, additionally, hours worked are longer. It follows that workers are to the right of their labour supply curves, working longer hours than they would choose at given wage rates. Second, where workers are able to bargain for contract curve outcomes which are superior to the competitive outcome, wages are greater than competitive wages and hours worked are less. This is consistent with the union-sector model developed in Oswald and Walker (1993). Third, the worse are the worker's alternative employment opportunities, the lower will be the alternative utility level and hence the further will the contract curve extend downwards away from the competitive outcome. Hence, we would expect that hours worked will be longer and wage rates will be lower the greater is the local unemployment 
rate. Fourth, we have indicated that hours are more likely to exceed desired hours the more hours are actually worked. We have argued that the empirical evidence and analysis presented by Stewart and Swaffield (1995, 1997), based on data from the BHPS of 1991 are consistent with a number of predictions from the model developed in the current paper.

It has recently been observed that not only are average male hours worked longer in the UK than in other EU countries, but also that only in the UK is it the case that average hours rose in the latter part of the last century - during a period of persistently high unemployment and decreasing union bargaining power. Within the framework of the model we have developed in this paper, it is not surprising to find rising hours associated with deteriorating employment prospects for workers, coupled with a shift in bargaining power towards employers. Finally, we have noted that a prediction of the model is that only by implementing maximum hours and minimum wage regulations simultaneously is it likely that workers can benefit from these interventions. Thus, from a low-paid over-worked worker's perspective, the policy combination of the minimum wage and the EU working time directive - both approved by the UK Parliament in 1998 - represents a happy coincidence. 


\section{References}

Eurostat (1993) - Labour Force Survey Results, 1991 (Bruxelles).

Eurostat (2001) - Labour Force Survey Results, 1999 (Bruxelles).

Metcalf, D. (1999), "The Low Pay Commission and the National Minimum Wage," Economic Journal, 109, pp. F46-66.

A. J. Oswald and I. Walker (1993), "Labour supply, contract theory and unions," Working Paper, November, Institute for Fiscal Studies.

A. J. Oswald (1995), personal communication.

B. N. Stern (1986), "On the specification of labour supply functions," in Unemployment, Search and Labour Supply, (Blundell, R. W. and Walker, I., Eds), CUP, Cambridge.

M. B. Stewart and J. K. Swaffield (1995), "Constraints on desired hours of work, trade unions and the length of the working week for British men," Working Paper, October, University of Warwick.

M. B. Stewart and J. K. Swaffield (1997), "Constraints on the desired hours of work of British men," Economic Journal, 107, pp. 520 - 535. 


\section{Table 1}

Hours Ususally worked per week, 1991 and 1999

Male employees working full-time

\begin{tabular}{lccc}
\hline Country & Average & \% working & Average \\
& Hours & 46 hours or more & Hours \\
& 1991 & 1991 & 1999 \\
& (All workers) & ("Industry" only) & (All workers) \\
\hline
\end{tabular}

$\begin{array}{lrrr}\text { Belgium } & 38.5 & 2.5 & 39.1 \\ \text { Denmark } & 38.9 & 3.8 & 39.6 \\ \text { France } & 40.4 & 6.2 & 40.2 \\ \text { Germany } & 40 & 4.8 & 40.5 \\ \text { Greece } & 41 & 12.4 & 41.7 \\ \text { Ireland } & 41.7 & 12.5 & 41.3 \\ \text { Italy } & 39.8 & 8.6 & 39.7 \\ \text { Luxembourg } & 40.4 & 3.1 & 40.5 \\ \text { Netherlands } & 39.1 & 1.2 & 39.2 \\ \text { Portugal } & 42.7 & 5.8 & 41.5 \\ \text { Spain } & 40.9 & 3.9 & 41.1 \\ & & & \\ \text { UK } & 45.2 & 34.8 & 45.2 \\ \text { Austria } & & & 40.3 \\ \text { Finland } & & & 40.1 \\ \text { Sweden } & & & \\ \text { EU average } & & & \end{array}$

Sources: Stewart and Swaffield (1997) for 1991 data (see also Eurostat (1993)) and Eurostat (2001) for 1999 data. 


\section{Table 2}

Hours preferences, BHPS, 1991-1999

Male employees aged 21-64

Would prefer

to work

\begin{tabular}{lrrrrrrrrr}
\hline & 1991 & 1992 & 1993 & 1994 & 1995 & 1996 & 1997 & 1998 & 1999 \\
Fewer & $\%$ & $\%$ & $\%$ & $\%$ & $\%$ & $\%$ & $\%$ & $\%$ & $\%$ \\
More & 36.2 & 34.2 & 35.6 & 36.3 & 37.9 & 36.7 & 35.5 & 36.7 & 38.6 \\
Same & 7.4 & 8.5 & 7.9 & 7.9 & 7.7 & 7.4 & 7.5 & 7.4 & 6.7 \\
& 56.4 & 57.3 & 56.5 & 55.8 & 54.4 & 55.9 & 58 & 55.9 & 54.7 \\
Total & & & & & & & & & \\
& 2204 & 2062 & 1939 & 1962 & 1988 & 2089 & 2162 & 2443 & 3355
\end{tabular}

Source: BHPS, 1991-1999. 